\title{
Bisphosphonates Act on Rat Bone Resorption through the Mediation of Osteoblasts
}

\author{
Malika Sahni, Harald L. Guenther, Herbert Fleisch, Pascal Collin, and T. John Martin * \\ Department of Pathophysiology, University of Berne, CH-3010 Berne, Switzerland; \\ and * St. Vincent's Institute of Medical Research, Melbourne 3065, Australia
}

\begin{abstract}
Bisphosphonates are generally considered to act on bone resorption by binding to bone mineral and subsequently inhibiting the activity of the osteoclasts which ingest them. This has been supported by the fact that bisphosphonates adsorbed on mineralized tissue inhibit the resorbing activity of isolated osteoclasts in vitro. However, the effectiveness of different bisphosphonates determined in this system does not reflect their relative potencies in vivo. Employing the well-described isolated osteoclast resorption pit assay, with ivory as the resorption substrate, we show here that this lack of correlation prevails only when the bisphosphonates are added to the mineral before addition of osteoclasts, but not when the cells are treated for a short time ( $5 \mathrm{~min}$ ) before allowing them to adhere onto ivory. By using this approach with five different bisphosphonates, a stringent correlation of relative potencies was obtained with those found, both in the rat and in the human, in vivo. Furthermore, by using an osteoblastic cell line (CRP 10/30) which is a powerful promoter of osteoclastic resorption in vitro, we obtained evidence that the inhibitory effect of bisphosphonates was the result of an action on osteoblasts rather than on osteoclasts. Thus, in experiments in which the osteoblastic cells were pretreated for $5 \mathrm{~min}$ with bisphosphonates and then cocultured with osteoclasts, inhibition of osteoclastic resorbing activity was obtained. Moreover, it was found that this treatment resulted in a decrease of the stimulatory effect found in CRP $10 / 30$-conditioned medium. In conclusion the present study shows that part of the osteoclast inhibiting action of the bisphosphonates is mediated through an action on osteoblasts. ( $J$. Clin. Invest. 1993. 91:2004-2011.) Key words: coculture • osteoblast-derived osteoclast-stimulating activity • osteoclasts • parathyroid hormone $\bullet$ resorption pit assay
\end{abstract}

\section{Introduction}

Bisphosphonates are analogues of pyrophosphate with a potent inhibitory effect on bone resorption (1). They have been established as therapeutic agents in many bone disorders character-

Dr. Collin's present address is Laboratoire de Biologie et Odontologie, SDI CNRS 6326, F-75270 Paris Cedex 06, France. Dr. Martin is on leave in the Department of Pathophysiology, University of Berne.

Address reprint requests to Dr. H. L. Guenther, Department of Pathophysiology, University of Berne, Murtenstrasse 35, CH-3010 Berne, Switzerland.

Received for publication 10 August 1992 and in revised form 21 December 1992.

J. Clin. Invest.

(c) The American Society for Clinical Investigation, Inc.

$0021-9738 / 93 / 05 / 2004 / 08 \quad \$ 2.00$

Volume 91, May 1993, 2004-2011 ized by increased resorption, such as Paget's disease (see review [2]), tumoral bone disease (see review [3]), and recently, osteoporosis as well (4-7). The mechanisms by which bisphosphonates inhibit bone resorption, however, remain to be clarified.

Because these compounds adsorb very effectively to hydroxyapatite (8), a feature that has been exploited for their use as bone-scanning agents, the inhibitory effect of bisphosphonates has principally been attributed to a metabolic injury of mature osteoclasts when they ingest bisphosphonates bound to bone (3). This mode of action was supported by the finding that osteoclasts acquire a degenerative morphological appearance and change in function not only in vivo (9) but also when cultured on bisphosphonate-coated bone or bone particles ( 10 , 11). Recently, it was shown that alendronate is localized densely under osteoclasts in vivo (12). This study as well as others (13), however, showed no differences in potency among compounds that displayed very different potencies in vivo, thus raising questions about the proposed mechanisms. Because there is evidence that bisphosphonates act on cells other than osteoclasts, for example, in the acute-phase reaction that they induce (14), it is conceivable that some of their effects may not be the result of direct actions on the osteoclast, but of indirect effects through other cells that can affect osteoclastmediated bone resorption.

In order to investigate whether bisphosphonates exert direct effects on bone cells unrelated to mineral adsorption, we undertook to determine the effect of treatment of disaggregated osteoclasts with bisphosphonates before their adherence onto the mineral surface. A 5-min treatment resulted in inhibition of resorption, and the responsiveness to a series of bisphosphonates at concentrations between $10^{-11}$ and $10^{-6} \mathrm{M}$ correlated well with the dose responsiveness to the same agents in vivo. Furthermore, evidence was obtained that the osteoblasts are the target cells of the bisphosphonates in mediating this response.

\section{Methods}

Materials. Medium 199 with Hanks' salts and 20 mM Hepes, (M199), minimum essential medium with Earle's salts ( $\mathrm{MEM} ; 2.2 \mathrm{~g} \mathrm{NaHCO}_{3}$ / liter) and gentamicin were purchased from Gibco AG, Basel, Switzerland. The bisphosphonates, 1-hydroxy-3(methylpentylamino)-propylidenebisphosphonic acid (BM 21.0955),' 3-amino-1-hydroxypropylidenebisphosphonic acid (pamidronate), and dichloromethylenebisphosphonic acid (clodronate) were gifts from Boehringer Mannheim GmbH, Mannheim, Federal Republic of Germany. 1-Hydroxyethylidene-bisphosphonic acid (etidronate) and 4-amino-1-hydroxy-butylidenebisphosphonic acid (alendronate) were gifts from In-

1. Abbreviations used in this paper: BM 21.0955, 1-hydroxy-3(methylpentylamino)-propylidenebisphosphonic acid; TRAP, tartrate-resistant acid phosphatase. 
stituto Gentili, Pisa, Italy. Stock solutions of bisphosphonates were prepared by dissolving them in $0.9 \% \mathrm{NaCl}$ at a concentration of 2 $\times 10^{-3} \mathrm{M}$. The $\mathrm{pH}$ of the individual solutions was adjusted to 7.4 with $\mathrm{NaOH}$. When needed, the above solutions were diluted with M199 and subsequently sterilized. Bovine parathyroid hormone (bPTH 1-34) was purchased from Bachem AG, Basel, Switzerland. Salmon calcitonin was gift from Sandoz, Basel, Switzerland. Plastic tissue culture plates (Costar, Cambridge, MA) were purchased from Technorama AG, Wallisellen, Switzerland.

Isolation and culture of osteoclasts. Osteoclasts were isolated from femurs of 1-day-old rats (Wistar) as previously described (15). Briefly, after killing the animals, femurs were dissected and freed of adherent soft tissue. Thereafter the bones were cut across their epiphysis and the bone marrow was removed by using a size 10 dental needle $(100 \mu \mathrm{m}$ in diameter). The femurs were then transferred to a dish containing $1 \mathrm{ml}$ M199 supplemented with $0.5 \%$ gentamicin. Osteoclasts were gently released from the femurs under constant agitation using in succession calibrated dental needles of size 20 and 30 . The movement of each needle occurred parallel to the longitudinal axis starting from the marrow cavity to the periosteum of the femur. With four femurs this procedure took no longer than $10 \mathrm{~min}$. The resulting osteoclast suspension, from four femurs, was adjusted to a volume of $2 \mathrm{ml}$ with M199. Then $500 \mu \mathrm{l}$ of the cell preparation was added to eight ivory slices kept in individual plastic wells $(2.0 \times 1.0 \mathrm{~cm})$. After a 25 -min incubation at $37^{\circ} \mathrm{C}$ and $5 \% \mathrm{CO}_{2}$, nonadherent cells were removed by lateral agitation. Then, eight slices for control and eight for each treated group were individually placed into single wells of a 24-well plastic tissue culture plate to which $500 \mu$ l of either control or test media were added. The cultures were carried out in MEM supplemented with $10 \%$ FBS for $24 \mathrm{~h}$ at $37^{\circ} \mathrm{C}$ and $5 \% \mathrm{CO}_{2}$.

Preparation of ivory slices. Elephant ivory (kindly donated by Dr. D. Ruedi, Basel Zoo, Switzerland) was used as mineral substrate to assess osteoclast resorption activity. The ivory was cut into $4 \times 4 \times 0.1$ $\mathrm{mm}$ slices with an Isomet low-speed saw (Buehler Instruments, Evanston, IL). The resulting slices were cleaned by ultrasound for $30 \mathrm{~min}$ in deionized water. Thereafter, the ivory pieces were air-dried, gas-sterilized, and subsequently degassed under vacuum for $12 \mathrm{~h}$.

Measurement of osteoclast resorption activity. After the 24-h culture period, the ivory slices were freed of all adherent cells by ultrasound in $70 \%$ isopropanol. The slices were then washed, air-dried, and sputter-coated with gold (SCD 004 Coater, Balzers, Liechtenstein). The number of resorption pits on each ivory slice was enumerated by using either a light microscope with a tangential light or a model S200 scanning electron microscope (Cambridge Instruments, Cambridge, UK). The magnification used to count the pit number was $\times 200$ and $\times 601$, respectively. A pit was defined as a depression in the ivory surface with a continuous rim and an area of at least $240 \mu \mathrm{m}^{2}$. Pit areas were determined from scanning electron microscope photographs (Fig. 1) by tracing the outline of the concavity onto graph paper. Osteoclast resorption activity was expressed as total number of excavations per eight slices which correspond to a surface area of $128 \mathrm{~mm}^{2}$. To ensure that the pit analysis was carried out in an unbiased manner, the reader was in the great majority of cases unaware of the treatment. Some experiments were counted by two persons, the correlation being excellent.

Influence of bisphosphonates on the resorption activity of isolated osteoclasts. The effects of bisphosphonates on the resorption activity of osteoclasts was examined by presenting the compounds to the cells either directly or bound to the mineral surface of ivory. In the former case, within $2 \mathrm{~min}$ of osteoclast isolation, $250 \mu$ l of osteoclast suspension was mixed with $250 \mu \mathrm{l}$ of bisphosphonate-containing solutions of various concentrations. After $5 \mathrm{~min}$ incubation at room temperature, cells were washed twice with $15 \mathrm{ml} \mathrm{M199}$ and then were centrifuged at $150 \mathrm{~g}$ for $10 \mathrm{~min}$. The resulting cell pellets were resuspended in $500 \mu \mathrm{l}$ of M199 and subsequently added to the ivory slices for adherence. After 25 min nonadherent cells were removed and osteoclasts cultured for $24 \mathrm{~h}$ in MEM supplemented with 10\% FBS.

In the case where the bisphosphonates were presented to the osteo-
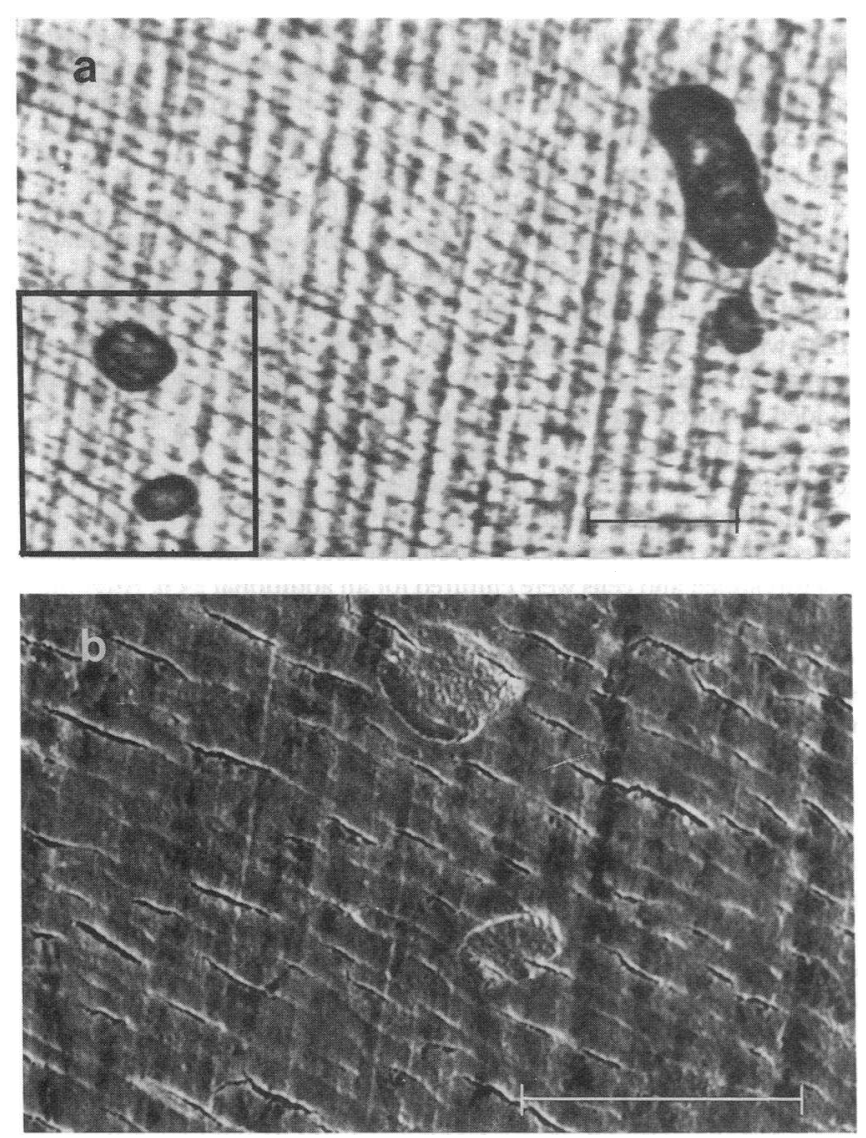

Figure 1. Microphotographs of osteoclast resorption pits formed on an ivory slice after 24-h culture. ( $a$ ) Four pits under light microscopy; the bar represents $50 \mu \mathrm{m}$. (b) A scanning electron microscope photo of the marked filed in $a$; the bar represents $50 \mu \mathrm{m}$.

clasts bound to mineral, ivory slices were incubated with different bisphosphonates of various concentrations for $25 \mathrm{~min}$ at $37^{\circ} \mathrm{C}$ and $5 \%$ $\mathrm{CO}_{2}$. Then $500 \mu \mathrm{l}$ of osteoclast suspension were added to the pretreated and subsequently washed ivory slices. After 15 or 25 min of settlement, as detailed in individual experiments, nonadherent cells were removed and osteoclasts cultured as described above.

Effect of osteoblast-conditioned medium and PTH on isolated osteoclasts. Osteoblast-conditioned medium was prepared from the wellcharacterized rat osteoblast cell line CRP 10/30 (16) as previously described (15). Briefly, CRP 10/30 cells were plated at a density of $10^{4}$ cells $/ \mathrm{cm}^{2}$ in $75-\mathrm{cm}^{2}$ tissue culture flasks where they were allowed to grow to confluence in MEM supplemented with $10 \%$ FBS and antibiotics. Medium was changed after every third day. At confluence, medium was removed and cells washed twice with $25 \mathrm{ml}$ PBS. Thereafter fresh MEM without FBS was added to the culture. After $24 \mathrm{~h}$ of incubation the medium was collected, centrifuged at $250 \mathrm{~g}$, and subsequently tested in the osteoclast bioassay.

To examine the effect of osteoblasts on the osteoclast resorption activity, we added bPTH(1-34)- or CRP 10/30-conditioned medium to the osteoclast resorption pit assay. Based on the assumption that osteoclasts settle more rapidly to the substrate than osteoblasts, equal volumes of suspended osteoclasts from a single preparation were added to three groups of ivory slices. Each group was then incubated for either 15,25 , or $120 \mathrm{~min}$. After the incubation, the slices were freed of nonadherent cells and a group of four slices each were incubated for $24 \mathrm{~h}$ in either $500 \mu \mathrm{l}$ of MEM containing PTH $\left(10^{-8} \mathrm{M}\right)$ and $10 \%$ FBS or with $500 \mu$ l of medium conditioned by CRP $10 / 30$ cells. As controls four slices each were incubated in MEM with or without $10 \%$ FBS. 
Effect of conditioned media from bisphosphonate-treated osteoblasts on osteoclast resorption activity. The osteoblast cell line CRP $10 / 30$ was cultured under identical conditions to those described above. In order to determine whether the treatment of CRP $10 / 30$ cells with bisphosphonates influences the ability of conditioned media to stimulate osteoclastic resorption activity, confluent monolayer osteoblasts were incubated with $10^{-7} \mathrm{M} \mathrm{BM} 21.0955$ or $10^{-6} \mathrm{M}$ clodronate for $5 \mathrm{~min}$ at $37^{\circ} \mathrm{C}$ and $5 \% \mathrm{CO}_{2}$. After $5 \mathrm{~min}$ of treatment, cells were washed twice with $20 \mathrm{ml}$ of MEM without serum. Thereafter fresh MEM without FBS was added to the osteoblast culture. After $24 \mathrm{~h}$ of incubation, media were collected and fresh MEM without FBS was readded to the confluent osteoblasts. After an additional 24-h incubation media were collected again and both 24 - and 48-h media samples were tested in the osteoclast resorption assay.

Osteoblast-osteoclast coculture. CRP 10/30 cell cultures were carried out as described above. At confluence, fresh medium without FBS was added and cells were cultured for an additional $24 \mathrm{~h}$. After the removal of the medium, cells were trypsinized, washed with MEM or M199, and centrifuged at $250 \mathrm{~g}$ for $10 \mathrm{~min}$. The cell pellet was either resuspended $\left(6 \times 10^{5}\right.$ cells $\left./ \mathrm{ml}\right)$ in MEM for coculture with bisphosphonate pretreated osteoclasts, or in M199 where untreated osteoclasts were cultured with bisphosphonate pretreated osteoblasts. In the latter case, $2 \mathrm{ml}$ of CRP 10/30 cell suspension prepared as described above were incubated for $5 \mathrm{~min}$ with $2 \mathrm{ml}$ of M199 containing either no bisphosphonates (controls) or BM 21.0955 and clodronate at concentrations ranging from $2 \times 10^{-7}$ to $2 \times 10^{-11} \mathrm{M}$ and $2 \times 10^{-6}$ to $2 \times 10^{-9}$ $M$, respectively. Thereafter, cells were washed twice with $40 \mathrm{ml}$ of M199 and then centrifuged for $10 \mathrm{~min}$ at $250 \mathrm{~g}$. The cell pellet was resuspended in MEM and subsequently added to individual wells each containing one ivory slice with adherent osteoclasts. The final volume per well and slice was $500 \mu \mathrm{l}$ of medium containing $3 \times 10^{5} \mathrm{CRP} 10 / 30$ cells. The coculture was carried out for $24 \mathrm{~h}$ in MEM free of FBS.

To determine the effect of osteoblasts on BM 21.0955- and clodronate-treated osteoclasts, cells from the same osteoclast suspension prepared for the coculture experiment described above were incubated with or without BM 21.0955 and clodronate, for $5 \mathrm{~min}$ at the same concentrations used for treatment of CRP 10/30 cells. After the 25min cell attachment period, $3 \times 10^{5} \mathrm{CRP} 10 / 30$ cells per $500 \mu \mathrm{l}$ of MEM were added to each well. The coculture was carried out for $24 \mathrm{~h}$ in MEM without FBS. In order to determine whether the magnitude of the bisphosphonate effect on osteoclast activity is influenced by the number of osteoblasts used in the coculture, we added various amounts of CRP $10 / 30$ cells $\left(3 \times 10^{5}, 5 \times 10^{4}\right.$, or $1 \times 10^{4}$ cells $/ 500 \mu$ per slice $)$

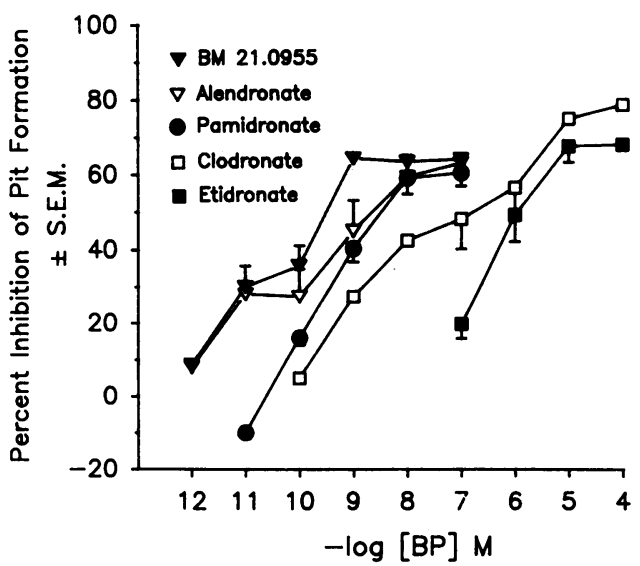

Figure 2. Inhibitory effect of various bisphosphonates on osteoclast activity after a short period of treatment $(5 \mathrm{~min})$ of osteoclast suspension in the absence of ivory (details in Methods). Results are the mean percent inhibition \pm SEM obtained from three individual experiments. The number of resorption pits on control slices was equal to $66 \pm 9$ per $128-\mathrm{mm}^{2}$ ivory. to adherent osteoclasts which had been pretreated for $5 \mathrm{~min}$ with $10^{-7}$ M BM 21.0955.

Determination of the number of osteoclasts and other cells adhering to the ivory surface. Tartrate-resistant acid phosphatase (TRAP)-positive cells (mononuclear or multinucleated) which had adhered to the ivory slice after $25 \mathrm{~min}$ or $24 \mathrm{~h}$ of incubation time were quantified as previously reported $(17,18)$. Furthermore, the number of osteoblasts per ivory slice, identified as alkaline phosphatase-positive mononuclear cells (Sigma Kit, Sigma Chemical Co., St. Louis, MO) was assessed after 15, 25, and 120 min of settlement of the osteoclast suspension, using the mean count of cells within the area enclosed by a standard reticule at a magnification of $\times 200$. Four fields were counted per slice with each representing $1 / 54(\times 200)$ of the total ivory slice area.

Statistical analysis. In each experiment for treatment and for control we used a single osteoclast suspension from the same animal group. The data are presented as total number of pits scored per eight or four slices. The difference between the means of individual experiments, treated versus control, was performed with the two-tailed Student's test.

\section{Results}

Treatment of osteoclast suspension with bisphosphonates in the absence of mineral. The treatment of the osteoclast suspension with bisphosphonates for $5 \mathrm{~min}$ and washing twice before settling onto ivory led to a dose-dependent inhibition of pit formation. A 35\% reduction in pit number, equalling half maximal inhibition for most bisphosphonates, was obtained at concentrations of $10^{-11} \mathrm{M}$ for BM 21.0955 and $10^{-6} \mathrm{M}$ for etidronate (Fig. 2). The order of potency for five bisphosphonates was found to be BM $21.0955>$ alendronate $>$ pamidronate $>$ clodronate $>$ etidronate, a finding that correlates well with the relative potencies obtained, in vivo (Table I).

Analysis of pit areas revealed that treatment of cells for 5 min with $10^{-7} \mathrm{M}$ BM 21.0955 not only caused a reduction in pit numbers from $26 \pm 4$ to $9 \pm 1$ pits $/ 64 \mathrm{~mm}^{2}(P<0.005)$ but also a diminution of pit areas from $658 \pm 52 \mu \mathrm{m}^{2}$ per pit in the control group to $342 \pm 49 \mu \mathrm{m}^{2}$ per pit in the BM 21.0955 treated group $(P<0.01)$.

Cultivation of the osteoclast suspensions with $10^{-7} \mathrm{M} \mathrm{BM}$ 21.0955 or $10^{-6} \mathrm{M}$ clodronate for $5 \mathrm{~min}$ showed no effects on the number of either mono- or multinucleated TRAP-positive cells or on the number of osteoblasts (ALP-positive cells) to adhere to the ivory surface during the 25-min settling period.

After $24 \mathrm{~h}$ of culture the number of osteoblasts and TRAP-

Table I. Antiresorbing Potency of Bisphosphonates In Vitro and In Vivo

\begin{tabular}{lccr}
\hline & & \multicolumn{2}{c}{ Relative potency } \\
\cline { 3 - 4 } Bisphosphonates & $\begin{array}{c}50 \% \text { inhibition } \\
\text { in vitro }\end{array}$ & $\begin{array}{c}\text { In } \\
\text { vitro }\end{array}$ & $\begin{array}{c}\text { In } \\
\text { vivo }\end{array}$ \\
\hline & $M$ & & \\
Etidronate & $1 \times 10^{-6}$ & 1 & 1 \\
Clodronate & $1.5 \times 10^{-7}$ & 8 & 10 \\
Pamidronate & $3 \times 10^{-9}$ & 550 & 100 \\
Alendronate & $2 \times 10^{-9}$ & 700 & 1,000 \\
BM 21.0955 & $3.5 \times 10^{-10}$ & 5,000 & 10,000
\end{tabular}

A $50 \%$ inhibition of total inhibition of osteoclastic resorption activity for the five bisphosphonates after a 5-min treatment of the osteoclast was determined from the data shown in Fig. 2. The data for in vivo potencies were taken from Muehlbauer et al. 1991 (25). 
Table II. Effects of BM 21.0955 and Clodronate on the Number of TRAP-positive Mono- and Multinucleated Cells and Osteoblasts Found on Ivory after 25-min Settlement and after $24 \mathrm{~h}$ of Culture

\begin{tabular}{cllcr}
\hline \multirow{2}{*}{$\begin{array}{c}\text { Time after } \\
\text { treatment }\end{array}$} & \multicolumn{1}{c}{$\begin{array}{c}\text { Bisphosphonates } \\
\text { (5-min treatment) }\end{array}$} & Number TRAP-positive cells* & Mononuclear & Osteoblasts* $^{*}$ \\
\cline { 4 - 5 } 25 -min settlement & Control & $126 \pm 2$ & $1,411 \pm 24$ & $3,655 \pm 84$ \\
& BM 21.0955 $\left(10^{-7} \mathrm{M}\right)$ & $123 \pm 4$ & $1,405 \pm 40$ & $3,659 \pm 92$ \\
& Clodronate $\left(10^{-6} \mathrm{M}\right)$ & $125 \pm 3$ & $1,410 \pm 18$ & $3,638 \pm 128$ \\
$24-\mathrm{h}$ culture & Control & $162 \pm 3^{\ddagger}$ & $426 \pm 19$ & $6,271 \pm 296$ \\
& BM 21.0955 $\left(10^{-7} \mathrm{M}\right)$ & $145 \pm 6$ & $410 \pm 16$ & $6,268 \pm 310$ \\
& Clodronate $\left(10^{-6} \mathrm{M}\right)$ & $126 \pm 12^{\S}$ & $414 \pm 18$ & $6,255 \pm 212$ \\
\hline
\end{tabular}

${ }^{*}$ No. of cells are expressed per $64 \mathrm{~mm}^{2}$ of ivory surface. Values are means \pm SEM of three individual experiments. ${ }^{\ddagger} P<0.05$ vs. control $(24 \mathrm{~h})$.

${ }^{\S} P<0.01$ vs. control $(24 \mathrm{~h})$.

positive multinucleated cells on the ivory increased whereas the number of TRAP-positive mononuclear cells decreased (Table II). This enhancement of numbers of osteoblasts or decrease of mononuclear TRAP-positive cells was not influenced by bisphosphonates. However, the increase in TRAPpositive multinucleated cells obtained in the control group was prevented by BM 21.0955 and by the clodronate treatment (Table II).

The treatment of osteoclast suspension with BM 21.0955 at $10^{-7} \mathrm{M}$ or with clodronate at $10^{-6} \mathrm{M}$ resulted in maximum inhibition of resorption of up to $65 \% \pm 5$ and $56 \% \pm 4$ respectively. Addition of calcitonin to the bisphosphonate treated osteoclasts throughout the culture period resulted in maximum inhibition of up to $96 \% \pm 2$. If calcitonin $\left(10^{-9} \mathrm{M}\right)$ alone was added an inhibition of $84 \% \pm 10$ was obtained.

Effect of bisphosphonates bound to ivory on pit formation. The results obtained with cells cultured on bisphosphonatecoated ivory (Fig. 3) show that although pit formation was inhibited by the various bisphosphonates, the dose relationship seen with cells treated in the absence of mineral was essentially lost. Moreover, the magnitude of difference among the different compounds was greatly reduced. In the present system pamidronate was the most effective, followed by alendronate, BM 21.0955, clodronate, and etidronate. The settlement time

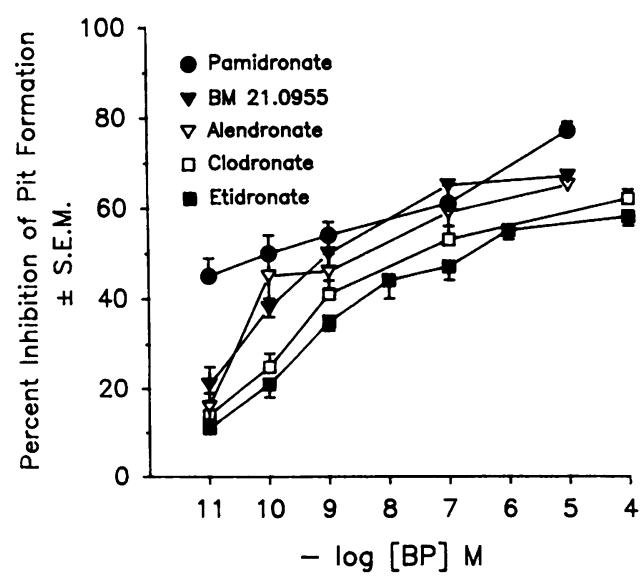

Figure 3. Inhibition of pit formation when osteoclast suspension was cultured on bisphosphonate-coated ivory. Each data point corresponds to the mean \pm SEM from three experiments. The number of pits on control slices was $61 \pm 8$ per $128-\mathrm{mm}^{2}$ ivory. appeared to make no difference to the response. Thus for example, after exposure of ivory to pamidronate $\left(10^{-7} \mathrm{M}\right) 54 \%$ and $69 \%$ inhibition of resorption was achieved with cells settled for $15 \mathrm{~min}$ in two separate experiments, and $66 \%$ and $63 \%$ inhibition with 25 min of settlement in the same experiments.

Effect of PTH and osteoblast conditioned medium on osteoclast resorption activity. Osteoblasts are known to be a major cell contaminant of isolated osteoclast preparations $(18,19)$. In that osteoblasts are known to influence osteoclast resorption activity when challenged with calciotropic hormones $(20,21)$, we assessed the functional purification of the osteoclast suspensions by adding PTH to cell preparations which were allowed 15,25 , or $120 \mathrm{~min}$ for cells to adhere to ivory (Fig. $4 a$ ). The latter time periods were selected based on the fact that osteoblasts due to their smaller cell size (diameter) settle less rapidly onto the culture surface (in our case ivory) than do osteoclasts. Therefore, the time designated for cell settlement determines the degree of osteoblast contamination of the isolated osteoclast preparations. The data presented in Fig. $4 a$ show that while PTH $\left(10^{-8} \mathrm{M}\right)$ did not affect pit formation when cells had adhered for $15 \mathrm{~min}$, the hormone caused a 2 - and 1.7-fold increase $(P<0.005)$ in the number of pits when cells had settled for 25 and $120 \mathrm{~min}$, respectively. In contrast to the above, medium conditioned by the osteoblastic CRP 10/30 cells enhanced osteoclast resorption activity also in the osteoclast cultures of 15-min cell settlements (Fig. $4 b$ ). In these

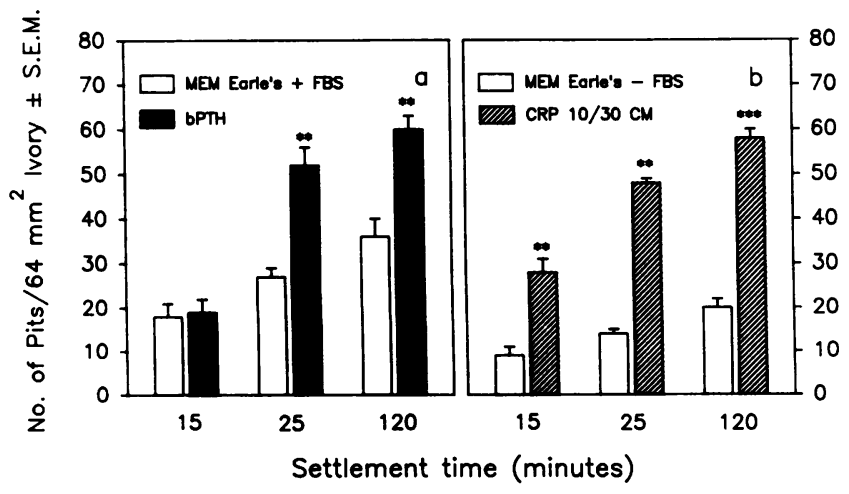

Figure 4. Effect of settlement time on the pit number formed by osteoclasts in the presence of $(a) 10^{-8} \mathrm{M}$ bPTH (1-34) and $(b)$ conditioned medium from CRP $10 / 30$ cells. Each value represents the mean \pm SEM from three individual experiments. ${ }^{* *} P<0.01$ vs. MEM Earle's + FBS and vs. MEM - FBS. ${ }^{* * *} P<0.001$ vs. MEM - FBS. 
experiments the number of osteoblasts per $64 \mathrm{~mm}^{2}$ of ivory surface after $15 \mathrm{~min}$ was $776 \pm 230$, after $25 \mathrm{~min}$ was $3,662 \pm 455$, and after 120 min was 4,476 \pm 403 .

Osteoblast-osteoclast coculture. Since the osteoclast preparations used in the present study are significantly contaminated by osteoblasts ( Table II) and because osteoblasts stimulate osteoclastic resorption activity and formation $(15,19,20)$, it was possible that the bisphosphonate effects shown in Fig. 2 resulted from their action on the contaminating osteoblasts rather than on the osteoclasts. To examine this possibility we used the well characterized osteoblast cell line CRP 10/30, which enhances resorption pit number in coculture with osteoclasts (e.g., Table III). When CRP $10 / 30$ cells $\left(3 \times 10^{5}\right.$ per slice) were pretreated for $5 \mathrm{~min}$ with various concentrations of BM 21.0955 or clodronate and thereafter cocultured for $24 \mathrm{~h}$ with adhering nontreated osteoclasts, a dose-dependent inhibition of resorption was determined with both bisphosphonates (Fig. 5). The latter results could not be reproduced with bisphosphonate-pretreated rat dermal fibroblasts (data not shown). In contrast, when isolated disaggregated osteoclasts were pretreated for $5 \mathrm{~min}$ with different concentrations of BM 21.0955 or clodronate and then cocultured after settling for 25 min onto ivory with $3 \times 10^{5}$ CRP 10/30 cells/slice (Fig. 6), the number of resorption pits of the control and bisphosphonate-treated groups were essentially identical. This suggests that addition of a sufficient number of osteoblasts can overcome the inhibitory effect of bisphosphonates, which is supported by experiments in which the number of added CRP $10 / 30$ cells were reduced to $5 \times 10^{4}$ and $1 \times 10^{4}$ per culture, respectively (Table III). While no inhibition was seen again when $3 \times 10^{5}$ osteoblasts were added per culture, the inhibition prevailed only when the osteoblast cell number was smaller than $3 \times 10^{5}$.

Furthermore, in view of the ability of CRP 10/30 conditioned medium to stimulate directly the resorption by osteoclasts settled for only 15 min (Fig. 4), we tested whether bisphosphonates reduced the production of this activity into the medium. Serum-free medium collected for $24 \mathrm{~h}$ after $5 \mathrm{~min}$ of treatment with BM $21.095510^{-7} \mathrm{M}$ or clodronate $10^{-6} \mathrm{M}$ showed reduced ability to stimulate resorption by osteoclasts

Table III. Influence of Various Amounts of Osteoblastic CRP 10/30 Cells, Cocultured with Isolated Osteoclasts, upon the Bisphosphonate-mediated Inhibition of Osteoclast Resorption Activity

\begin{tabular}{clc}
\hline $\begin{array}{c}\text { No. of CRP } \\
10 / 30 \text { cells } \\
\text { added per slice }\end{array}$ & $\begin{array}{c}\text { 5-min bisphosphonate } \\
\text { treatment of } \\
\text { suspended osteoclasts }\end{array}$ & $\begin{array}{c}\text { Pit } \\
\text { number }\end{array}$ \\
\hline $3 \times 10^{5}$ & Control & $30 \pm 6$ \\
$5 \times 10^{4}$ & BM 21.0955 $\left(10^{-7} \mathrm{M}\right)$ & $29 \pm 5$ \\
& Control & $17 \pm 4$ \\
$1 \times 10^{4}$ & BM 21.0955 $\left(10^{-7} \mathrm{M}\right)$ & $10 \pm 2^{*}$ \\
& Control & $11 \pm 3$ \\
& BM 21.0955 $\left(10^{-7} \mathrm{M}\right)$ & $5 \pm 1^{\ddagger}$ \\
\hline
\end{tabular}

The number of pits obtained without addition of CRP 10/30 cells was $6 \pm 1$. Pit number is expressed per $64 \mathrm{~mm}^{2}$ of ivory slice surface. Values are the mean \pm SEM of three separate experiments. ${ }^{*} P<0.05$ vs. control. ${ }^{\ddagger} P<0.01$ vs. control.

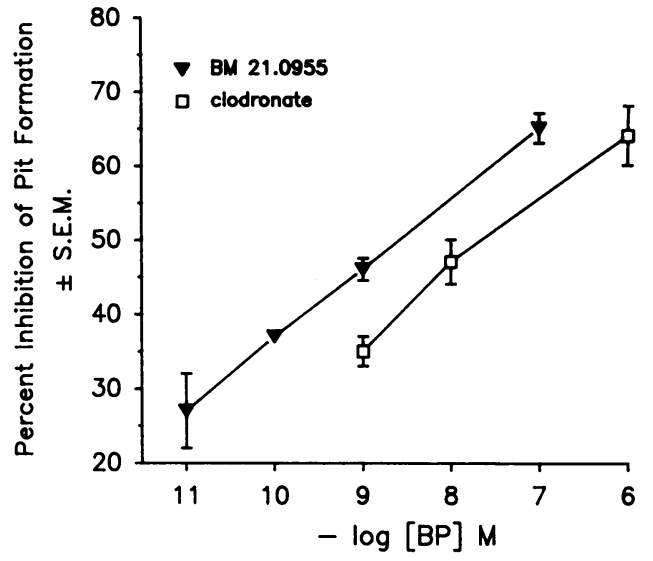

Figure 5. Pit formation by osteoclasts cocultured with bisphosphonatetreated CRP $10 / 30$ cells $(5 \mathrm{~min}$ ). Values represent the mean \pm SEM obtained from three individual experiments. In the control groups the number of resorption pits was $57 \pm 4$ per $64-\mathrm{mm}^{2}$ ivory.

settled on ivory for $25 \mathrm{~min}$ (Fig. 7). In these experiments, continuation of serum-free culture of CRP 10/30 to $48 \mathrm{~h}$ resulted in loss of production of resorption-stimulating activity into the medium (Fig. 7). Therefore, it was not possible to test for reversibility of the bisphosphonate effect.

\section{Discussion}

Bisphosphonates are potent inhibitors of bone resorption when tested in a variety of systems both in culture and in vivo. Although the precise mode of action of these compounds is still unclear, it is generally attributed to the direct inhibitory effect of bisphosphonate-coated bone on the ability of mature osteoclasts to resorb $(3,10,22)$. Indeed, bisphosphonates have a strong affinity for hydroxyapatite (8), and hence for bone, especially at the site of new bone formation. Thisis reflected in their use as scintigraphic agents to detect areas of high bone formation. Furthermore, it was shown recently that alendronate deposits preferentially under osteoclasts (12), and it was calculated that local concentrations could approach $1 \mathrm{mM}$ (12).

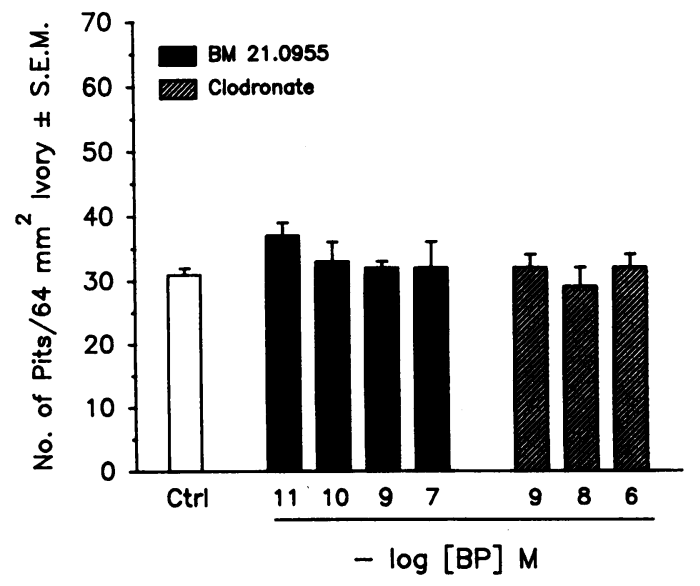

Figure 6. Effect of coculturing bisphosphonate-treated osteoclasts ( 5 min) with the CRP 10/30 cells on resorption as measured by pit formation. Each value corresponds to the mean of pit number \pm SEM derived from three experiments. 


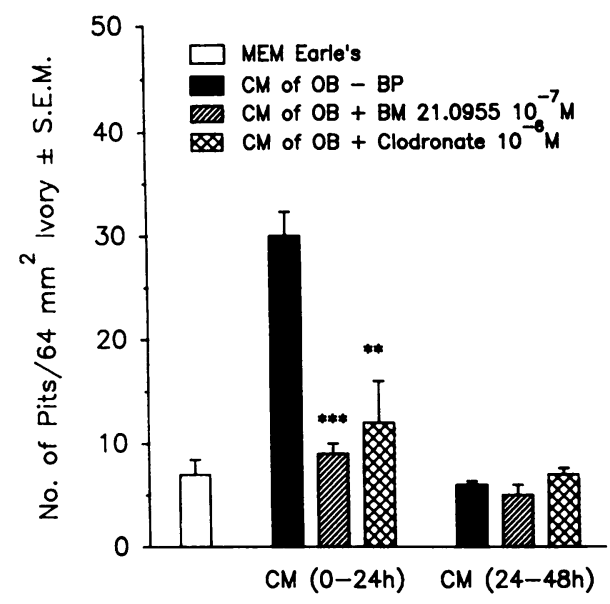

Figure 7. Effect of BP treatment on the ability of CRP $10 / 30$ cells to produce osteoclast-stimulating activity into the medium. $\mathrm{CM}$ denotes conditioned medium collected after 24 and $48 \mathrm{~h}$ after a 5-min treatment of CRP 10/30 cells with BM 21.0955 or clodronate. Each value represents the mean \pm SEM from three separate experiments. ${ }^{* *} P$ $<0.01$ vs. control CM. ${ }^{* * *} P<0.001$ vs. control CM.

However, previous studies using several techniques in vitro have failed to reproduce the relative potencies which various bisphosphonates display in vivo. This was the case in studies of the inhibition of bone resorption in organ cultures using fetal long bone explants (23), and especially in studies where the inhibition of mature osteoclasts was assessed with the compounds bound to the mineral surface (13).

Up to the present time, the only in vitro studies that have demonstrated a correlation with the inhibition observed in vivo depended upon recruitment of new osteoclasts on the bone surface (23), and the formation of multinucleated cells in human long-term bone marrow cultures (24). However, in vivo studies have shown that with bisphosphonate treatment the number of osteoclasts can increase despite a complete inhibition of bone resorption (25). Therefore, inhibition of osteoclast recruitment does not satisfactorily explain the action of these compounds in vivo.

The conflicting findings between in vivo and in vitro studies suggest that bisphosphonates do not operate solely through direct actions on osteoclast activity or recruitment, but through other mechanisms. They may involve other cell system(s) that may be related to bone resorption. Thus, it has been shown that bisphosphonates do affect also other cells involved in bone turnover, including osteoblasts $(26,27)$ and macrophages, of which both activity $(28)$ and proliferation $(29,30)$ are inhibited in vitro.

In this work we have demonstrated a correlation between the inhibitory activity of bisphosphonates in vitro and that which operates in vivo. Using the osteoclast resorption pit assay (18), we have shown that by altering the assay conditions it was possible to obtain inhibition of osteoclastic resorption activity at a bisphosphonate concentrations as low as $10^{-11} \mathrm{M}$, something which has not been previously possible. A 5-min exposure of a freshly isolated osteoclast preparation to bisphosphonates was found to be sufficient to produce this inhibitory effect. Moreover, in this system the relative efficacies of five bisphosphonates closely paralleled their relative potencies, in vivo. In contrast, no correlation with in vivo results was seen when the compounds were added to ivory before adding the osteoclast suspension, or when the bisphosphonates were added concurrently with the cells to the medium (data not shown). These results provide evidence for a direct effect of bisphosphonates on the cells present in the osteoclast population used, independent of the need for a contact of osteoclasts with bisphosphonate-containing mineral. While our data imply that bisphosphonates can influence osteoclast function independently of the mineral route, they do not preclude the possibility that osteoclasts are also inhibited, in situ, through ingestion of mineral containing the drugs. The latter effect was suggested by the finding that coating ivory with bisphosphonates results in the same extent of inhibition of osteoclastic resorption whether the osteoclast suspension were allowed to settle for 15 or 25 min onto the ivory surface.

The next question was to find out whether the compounds exerted their effect directly upon the osteoclasts or indirectly through other cells. It is now generally accepted that osteoblasts can stimulate osteoclast resorption activity (15, 20, 31). Many factors that stimulate bone resorption, such as PTH $(19,20)$, 1,25-dihydroxyvitamin $D_{3}(21)$, prostaglandin $E_{2}(32)$, interleukin 1 (33), and tumor necrosis factor- $\alpha$ (34), have been shown to act on this event through the release of an osteoblastderived osteoclast stimulating activity. Since our osteoclast populations adhering from 25 -min settlement periods are contaminated by other cells, among them osteoblasts, it is conceivable that the inhibitory effect seen was not due to an action on the osteoclasts, but on some of the contaminating cells, possibly osteoblasts. The role of contaminating osteoblasts is illustrated by the finding that PTH induced an increase in resorption only when the cell preparation containing the osteoclasts was allowed to adhere for $>15 \mathrm{~min}$. These results, which are in agreement with previous studies indicate that it requires $>15 \mathrm{~min}$ to allow sufficient number of osteoblasts to settle for the latter to affect osteoclasts after the PTH challenge $(18,19)$. The resorption stimulating effect obtained with conditioned medium of the osteoblastic clone CRP 10/30 when osteoclasts were settled for $15 \mathrm{~min}$ not only supports the above conclusion but accentuates the importance of osteoblasts in osteoclast-mediated resorption.

The hypothesis that the antiresorbing activity of the bisphosphonates on osteoclasts was mediated by osteoblasts was supported by the experiments with the osteoblastic cell clone CRP 10/30. This clone exhibits several characteristics of differentiated osteoblasts (16), and has recently been shown to synthesize an osteoclast-stimulating activity as assessed using the resorption pit assay (15). Thus when disaggregated osteoclasts were cocultured with bisphosphonate-treated CRP 10/ 30 cells, an inhibition of pit formation was obtained. However, this inhibition was not evident when the osteoclasts were treated for $5 \mathrm{~min}$ and subsequently cocultured with untreated CRP 10/30 cells. Moreover, the fact that BM 21.0955 inhibited osteoclast activity more strongly than clodronate, when CRP 10/30 cells were pretreated with the compounds before coculture, provides good evidence that the antiresorptive effect of bisphosphonates is osteoblast dependent. The fact that the difference in activity between BM 21.0955 and clodronate is less than the difference obtained when the osteoblast-osteoclast preparation is treated has, at present, no explanation. The finding that rat dermal fibroblasts treated with bisphosphonates did not produce the effects obtained with CRP 10/30 cells suggests 
that the inhibitory action of these compounds may be specific for osteoblasts.

It was interesting to note that no inhibition of resorption was observed when osteoclast suspensions treated with bisphosphonates were subsequently cocultured with untreated CRP 10/30 cells. This suggests that the effect of the bisphosphonate on the contaminating osteoblasts was overcome by the osteoclast-stimulating activity released from CRP 10/30 cells, which greatly outnumbered the osteoblasts that were contained in the osteoclast preparation. This is supported by the finding that a reduction of the number of CRP $10 / 30$ cells added to the osteoclast culture was paralleled by a diminution of osteoclaststimulating activity and a reduction of the bisphosphonate-induced inhibition. This explanation is consistent with data showing that PTH treatment prevented bisphosphonate-induced inhibition of bone resorption, perhaps by a mechanism which opposes the inhibition of the production of osteoblastderived osteoclast resorption stimulating activity (35).

It is not yet clear how bisphosphonates could gain access to osteoblasts in vivo. One possibility is that they come directly from the general circulation after their administration. The more likely explanation, consistent with their long duration of action, is that they are released from bone into the microenvironment of osteoblasts, either by passive diffusion or during resorption. The recent data on in vivo localization of alendronate (12) would be in consistent with this latter possibility.

Our results suggest that inhibition of the osteoblast-osteoclast pathway is an important component of the action of bisphosphonates. The relative importance in vivo of the two mechanisms, either direct inhibition of osteoclast activity and indirect inhibition through the osteoblast remains to be determined. The osteoblast-mediated activity opens new biochemical approaches to elucidate the precise cellular mechanism of action of these drugs, and hence for the development of new drugs inhibiting bone resorption. In addition, it may provide a novel approach to investigating the regulation of production of osteoblast-derived osteoclast-stimulating activity.

\section{Acknowledgments}

The authors thank M. Burren and B. Holinger for skillful technical assistance, and Heidi Triet for secretarial support. In addition, the School of Dentistry, University of Berne, is gratefully acknowledged for allowing us to use their scanning electron microscope.

This work has been supported by the Swiss National Science Foundation Grants No. 3.894.0.88 and 32.31272.91

\section{References}

1. Fleisch, H., R. G. C. Russell, and M. D. Francis. 1969. Diphosphonates inhibit hydroxyapatite dissolution in vitro and bone resorption in tissue culture and in vivo. Science (Wash. DC). 165:1262-1264.

2. Kanis, J. A. 1991. Drug used for the treatment of Paget's disease. In Pathophysiology and Treatment of Paget's Disease of Bone. J. A. Kanis, editor. Martin Dunitz Ltd., London. 159-216.

3. Fleisch, H. 1991. Bisphosphonates: pharmacology and use in the treatment of tumor-induced hypercalcaemic and metastatic bone disease. Drugs. 42:919944.

4. Reginster, J. Y., M. P. Lecart, R. Deroisy, N. Sarlet, D. Denis, D. Ethgen, J. Collette, and P. Franchimont. 1989. Prevention of postmenopausal bone loss by tiludronate. Lancet. 2:1469-1471.

5. Valkema, R., F.-J. F. E. Vismans, S. E. Papapoulos, E. K. J. Pauwels, and O. L. M. Bijvoet. 1989. Maintained improvement in calcium balance and bone mineral content in patients with osteoporosis treated with the bisphosphonate APD. Bone Miner. 5:183-192.

6. Storm, T., G. Thamsborg, T. Steiniche, H. K. Genant, and O. H. Soerensen. 1990. Effect of intermittent cyclical edidronate therapy on bone mass and fracture rate in women with postmenopausal osteoporosis. N. Engl. J. Med. 322:1265-1271.

7. Watts, N. B., S. T. Harris, H. K. Genant, R. D. Wasnich, P. D. Miller, R. D. Jackson, A. A. Licata, P. Ross, G. C. Woodson, M. J. Yanover, et al. 1990 Intermittent cyclical etidronate treatment of postmenopausal osteoporosis. $N$. Engl. J. Med. 323:73-79.

8. Jung, A., S. Bisaz, and H. Fleisch. 1973. The binding of pyrophosphate and two diphosphonates by hydroxyapatite crystals. Calcif. Tissue Res. 11:269-280.

9. Schenk, R., W. A. Merz, R. Muehlbauer, R. G. G. Russell, and H. Fleisch. 1973. Effect of ethane-1-hydroxy-1,1-diphosphonate (EHDP) and dichloromethylene diphosphonate $\left(\mathrm{Cl}_{2} \mathrm{MDP}\right)$ on the tibeal epiphysis and metaphysis of rats. Calif. Tissue Res. 11:196-214.

10. Flanagan, A. M., and T. J. Chambers. 1989. Dichloromethylenebisphosphonate $\left(\mathrm{Cl}_{2} \mathrm{MBP}\right)$ inhibits bone resorption through injury to osteoclasts that resorb $\mathrm{Cl}_{2} \mathrm{MBP}$-coated bone. Bone Miner. 6:33-43.

11. Carano, A., S. L. Teitelbaum, J. D. Konsek, P. H. Schlesinger, and H. C. Blair. 1990. Bisphosphonates directly inhibit the bone resorption activity of isolated avian osteoclasts in vitro. J. Clin. Invest. 85:456-461.

12. Sato, M., W. Grasser, N. Endo, R. Akins, H. Simmons, D. D. Thompson, E. Golub, and G. A. Rodan. 1991. Bisphosphonate action: alendronate localization in rat bone and effects on osteoclast ultrastructure. J. Clin. Invest. 88:20952105.

13. Sato, M., and W. Grasser. 1990. Effects of bisphosphonates on isolated rat osteoclasts as examined by reflected light microscopy. J. Bone Miner. Res. 5:3140

14. Adami, S., A. K. Bhalla, R. Dorizzi, F. Montesanti, S. Rosini, G. Salvagno, and V. Locascio. 1987. The acute-phase response after bisphosphonate administration. Calcif. Tissue Int. 41:326-331.

15. Collin, P., H. L. Guenther, and H. Fleisch. 1992. Constitutive expression of osteoclast-stimulating activity by normal clonal osteoblast-like cells: effects of parathyroid hormone and 1,25-dihydroxyvitamin $D_{3}$. Endocrinology. 131:11811187.

16. Guenther, H. L., W. Hofstetter, A. Stutzer, R. Muehlbauer, and H. Fleisch. 1989. Evidence for heterogeneity of the osteoblastic phenotype determined with clonal rat bone cells established from transforming growth factor- $\beta$ induced cell colonies grown anchorage independently in semisolid medium. Endocrinology. 125:2092-2102.

17. Brunk, U. T., and J. L. E. Ericsson. 1972. The demonstration of acid phosphatase in vitro cultured tissue cells: studies on the significance of fixation, tonicity and permeability. Histochem. J. 4:349-363.

18. McSheehy, P. M. J., and T. J. Chambers. 1986. Osteoblastic cells mediate osteoclastic responsiveness to parathyroid hormone. Endocrinology. 118:824828.

19. Evely, R. S., A. Bonomo, H. G. Schneider, J. M. Moseley, J. A. Gallagher, and T. J. Martin. 1991. Structural requirement for the action of parathyroid hormone-related protein (PTHrP) on bone resorption by isolated osteoclasts. $J$. Bone Miner. Res. 6:85-93.

20. McSheehy, P. M. J., and T. J. Chambers. 1986. Osteoblast-like cells in the presence of parathyroid hormone release soluble factor that stimulates osteoclastic bone resorption. Endocrinology. 119:1654-1659.

21. McSheehy, P. M. J., and T. J. Chambers. 1987. 1,25-dihydroxyvitamin $\mathrm{D}_{3}$ stimulates rat osteoblastic cells to release a soluble factor that increases osteoclastic bone resorption. J. Clin. Invest. 80:425-429.

22. Flanagan, A. M., and T. J. Chambers. 1991. Inhibition of bone resorption by bisphosphonates: interactions between bisphosphonates, osteoclasts, and bone. Calcif. Tissue Int. 49:407-415.

23. Boonekamp, P. M., L. J. A. van der Wee-Pals, M. M. L. van Wijk-van Lennep, C. W. Thesing, and O. L. M. Bijvoet. 1986. Two mode of action of bisphosphonates on osteoclastic resorption of mineralized matrix. Bone Miner. 1:27-39.

24. Hughes, D. E., B. R. MacDonald, R. G. G. Russell, and M. Gowen. 1989. Inhibition of osteoclast-like cell formation by bisphosphonates in long-term cultures of Human bone marrow. J. Clin. Invest. 83:1930-1935.

25. Muehlbauer, R. C., F. Bauss, R. Schenk, M. Janner, E. Bosies, K. Strein and H. Fleisch. 1991. BM 21.0955 , a potent new bisphosphonate to inhibit bone resorption. J. Bone Miner. Res. 9:1003-1011.

26. Ohya, K., S. Yamada, R. Felix, and H. Fleisch. 1985. Effect of bisphosphonates on prostaglandin synthesis by rat bone cells and mouse calvaria in culture. Clin. Sci. (Lond.). 69:403-411.

27. Stronski, S. A., L. Bettschen-Camin, A. Wetterwald, R. Felix, U. Trechsel, and $H$. Fleisch. 1988. Bisphosphonates inhibit 1,25-dihydroxyvitamin $D_{3}$-induced increase of osteocalcin in plasma of rats in vivo and in culture medium. Calcif. Tissue Int. 42:248-254.

28. Chambers, T. J. 1980. Diphosphonates inhibit bone resorption by macrophages in vitro. $J$. Pathol. 132:255-262. 
29. Cecchini, M. G., R. Felix, H. Fleisch, and P. H. Cooper. 1987. Effect of bisphosphonates on proliferation and viability of mouse bone marrow-derived macrophages. J. Bone Miner. Res. 2:135-142.

30. Cecchini, M. G., and H. Fleisch. 1990. Bisphosphonates in vitro specifically inhibit, among the hematopoietic series, the development of the mouse mononuclear phagocyte lineage. J. Bone Miner. Res. 5:1019-1027.

31. Rodan, G. A., and T. J. Martin. 1981. Role of osteoblasts in hormonal control of bone resorption: a hypothesis. Calcif. Tissue Int. 33:349-351.

32. Okuda, A., L. M. Taylor, and L. N. M. Heersche. 1989. Prostaglandin $E_{2}$ initially inhibits and then stimulates bone resorption in isolated rabbit osteoclast cultures. Bone Miner. 7:255-266.
33. Thomson, B. M., J. Saklatvala, and T. J. Chambers. 1986. Osteoblasts mediate interleukin 1 stimulation of bone resorption by rat osteoclasts. J. Exp. Med. 164:104-112.

34. Thomson, B., G. R. Mundy, and T. J. Chambers. 1987. Tumor necrosis factors $\alpha$ and $\beta$ induce osteoblastic cells to stimulate osteoclastic bone resorption. J. Immunol. 138:775-779.

35. Van der Pluijm, G., C. W. G. M. Löwik, H. De Groot, M. J. Alblas, L. J. A Van Der Wee-Pals, O. L. M. Bijvoet, and S. E. Papapoulos. 1991. Modulation of PTH-stimulated osteoclastic resorption by bisphosphonates in fetal mouse bone explants. J. Bone Miner. Res. 6:1203-1210. 